\title{
Heparin Therapy in Pediatric Patients: A Prospective Cohort Study
}

\author{
MAUREEN ANDREW, VELMA MARZINOTTO, PATTI MASSICOTTE, VICTOR BLANCHETTE, \\ JEFF GINSBERG, PAT BRILL-EDWARDS, PAT BURROWS, LEE BENSON, WILLIAM WILLIAMS, \\ MICHELLE DAVID, ANNETTE POON, AND KATHY SPARLING \\ Department of Pediatrics [M.A., P.M.], Pathology [M.A.], and Medicine [J.G., P.B.-E.], McMaster University, \\ Hamilton, Ontario; Divisions of Hematology [V.M., V.B., A.P.], Cardiology [L.B.], Surgery [W.W.], and \\ Radiology [P.B.], The Hospital for Sick Children, Toronto, Ontario; and Department of Hematology [M.D.], \\ Ste-Justine Hospital, Montreal, Quebec
}

\begin{abstract}
Current guidelines for heparin therapy in pediatric patients have been extrapolated from trials in adult patients without rigorous evaluation of efficacy and safety. We prospectively monitored consecutive pediatric patients receiving systemic doses of heparin over 10 mo at one institution using a predetermined nomogram to monitor maintenance therapy. Sixty-five consecutive children; 38 males and 27 females, received systemic doses of heparin. Thirty children had deep venous thrombosis and/or pulmonary embolism; 11 had arterial thrombi, most frequently after diagnostic angiography; and the remaining 24 received heparin prophylactically, for congenital heart disease. Twenty-nine (45\%) of the 65 patients were less than $1 \mathrm{y}$ of age and $22(34 \%)$ were $10 \mathrm{y}$ or older. Congenital heart disease was the predominant diagnosis under $1 \mathrm{y}$ and deep venous thrombosis in older children. After a bolus dose of $50 \mathrm{U} / \mathrm{kg}, 39 \%$ of children $(n=30)$ achieved a minimal level activated partial thromboplastin time (APTT). Sixty-eight percent of children achieved a minimal level APTT by $24 \mathrm{~h}$ and $81 \%$ by $48 \mathrm{~h}$. For all 65 children, APTT values were within the therapeutic range $43 \%$ of the time. APTT values outside the therapeutic range were twice as likely to be low as high. The average amount of heparin required to maintain therapeutic APTT values for children was $22 \mathrm{U} / \mathrm{kg} / \mathrm{h}: 28 \mathrm{U} / \mathbf{k g} / \mathrm{h}$ for infants $<1 \mathrm{y}$ and $20 \mathrm{U} / \mathrm{kg} / \mathrm{h}$ for the rest. Bleeding was rare $(2 \%)$ and mild. Documented recurrent thrombotic disease was more common $(7 \%)$ with associated morbidity. In summary, a commonly used protocol for administration of heparin to children was rigorously evaluated and shown to provide insufficient amounts of heparin in the first days of treatment. Average requirements of heparin per kilogram per hour were determined and will form the bases of future studies. (Pediatr Res 35: 78-83, 1994)
\end{abstract}

\section{Abbreviations}

APTT, activated partial thromboplastin time

CPB, cardiopulmonary bypass

HSC, Hospital for Sick Children

DVT, deep vein thrombosis

$\mathrm{V} / \mathrm{Q}$, ventillation perfusion scan

$P E$, pulmonary embolism
CHD, congenital heart disease

SLE, systemic lupus erythematosus

CBC, complete blood count

PT, prothrombin time

TPN, total parenteral nutrition

Depending upon the underlying problem, the anticoagulant heparin is administered in low doses or in higher "systemic" doses. Recommendations for the use of systemic dose heparin in adult patients are based upon the results of numerous randomized controlled trials (1). The guidelines for the use of systemic dose heparin in newborns and children with or at risk for thromboembolic complications have been directly extrapolated from recommendations for adults $(2,3)$. This practice has arisen because the administration of systemic dose heparin is rare enough in pediatric patients to hinder the performance of large clinical trials, yet common enough to present significant management dilemmas $(4,5)$.

There is some evidence that the guidelines for systemic dose heparin in adults may not be optimal in children. First, the clearance of heparin has been evaluated in animal models and in children and is significantly faster in the young compared to the adult (6-8). This may result in children requiring more heparin than adults to achieve the same heparin level. Second, thrombin generation is physiologically decreased during infancy and in some pediatric patients who may require heparin (9-11). The latter directly influences the effect of heparin on thrombin regulation and could thereby potentially alter the therapeutic range based on the APTT $(1,9,11,12)$.

Neither the populations that receive systemic dose heparin nor the amounts of heparin required to maintain a therapeutic level have been determined in children (13-17). Further, neither the incidence of significant bleeding nor recurrent thrombotic complications are known for children receiving systemic dose heparin. The objectives of this study were 2 -fold. First, we wanted to determine the epidemiological features of pediatric patients receiving systemic dose heparin. Second, we wanted to determine the clinical and laboratory response of pediatric patients to a uniform heparin protocol. The following study reports the first 65 consecutive pediatric patients treated with heparin over a 10 mo period at one institution.

\section{MATERIALS AND METHODS}

Correspondence: Dr. M. Andrew, McMaster University Medical Centre, Department of Pediatrics, Room 3N27A, 1200 Main Street West, Hamilton, Ontario, L8N 3Z5, Canada.

Supported by a Grant-in-Aid from the Heart and Stroke Foundation of Ontario and a Regional Medical Associates Scholarship. M.A. is a Career Scientist with the Heart and Stroke Foundation of Canada.
Patient Population. Consecutive pediatric patients treated with systemic dose heparin, (excluding patients undergoing CPB and angiographic procedures) at HSC, Toronto, Canada between July 1, 1991 and April 1, 1992 formed the patient population followed 
prospectively. Informed consent was not obtained because all patients required heparin therapy and the heparin protocol used reflected usual practice. The patient population could be easily divided into distinct groups according to the indication for heparin: 1) DVT, 2) arterial thrombosis, and 3) prophylactic heparin.

Children with DVT. All children with suspected DVT were initially evaluated with objective tests that consisted of venography and/or duplex/ultrasound. DVT was diagnosed when a persistent intraluminal filling defect was seen or a noncompressible venous segment by duplex ultrasound. PE was diagnosed when a high probability V/Q scan was seen (segmental or greater defect in perfusion with normal ventilation). Further radiographic evaluation depended upon the presenting symptoms. Demographic information was collected for each of these patients.

Children without DVT. Children without DVT consisted of patients with arterial thrombosis, usually after cardiac catheterization and children who did not have venous or arterial thrombi but received systemic amounts of heparin prophylactically. Demographic information was also recorded for these patients.

Age-matched controls. During the study period, healthy children at the Children's Hospital, Chedoke McMaster University Medical Centre, Hamilton, Ontario, Canada provided blood samples for in vitro assessments of heparin activity. From these children, a 3-mL blood sample for research purposes was obtained at the same time as preoperative blood work was drawn for minor elective surgery. This protocol was approved by the institutional ethics committee and informed consent was obtained from the parents.

For all children, platelet-poor plasma was obtained from whole blood anticoagulated with sodium citrate followed by centrifugation at $3000 \times g$ for $20 \mathrm{~min}$. Samples were aliquoted and frozen for future assay.

Coagulation Assays. All pediatric patients were evaluated initially with a baseline CBC, PT (Precision Biologicals, Halifax, Nova Scotia, Canada), and APTT (Precision Biologicals). Heparin concentrations were measured with either an antifactor $\mathrm{Xa}$ assay (18) or a thrombin clot time assay (19).

Evaluation of Heparin Protocol. The heparin protocol was extrapolated from protocols used in adult patients and reflected current clinical care (20). Heparin therapy was initiated with a bolus of $50 \mathrm{U} / \mathrm{kg}$ of heparin administered over $10 \mathrm{~min}$ followed by maintenance therapy initiated at $20 \mathrm{U} / \mathrm{kg} / \mathrm{h}$. Some children did not receive a bolus of $50 \mathrm{U} / \mathrm{kg}$ because they had recently received heparin prophylactically for specific procedures or operations. These children were placed on the maintenance phase at $20 \mathrm{U} / \mathrm{kg} / \mathrm{h}$. The duration of heparin therapy followed common practice which was 5 to $10 \mathrm{~d}$ for DVT and shorter duration for the other groups.

Heparin therapy was adjusted according to APTT values after a nomogram for all 65 children (Table 1). The APTT therapeutic range was 55 to $85 \mathrm{~s}$, which corresponded to a heparin level of 0.2 to $0.4 \mathrm{U} / \mathrm{mL}$ by protamine titration $(1,19)$. For all children, daily flow sheets were maintained to document the amount of heparin infusing, any changes in heparin dose, APTT values, and heparin levels if measured. In addition any complications were also detailed. The following parameters were analyzed: APTT values before treatment, postbolus APTT values, the values for the first therapeutic APTT, the percent of time the patients had therapeutic and nontherapeutic APTT values, and the average amount of heparin required to maintain a therapeutic APTT. In addition, the relationship between heparin levels and APTT values was determined ex vivo for the same patients.

Responsiveness to Heparin In Vitro. The relationship between APTT values and heparin levels was assessed in vitro using the same APTT reagent (Precision) as used to monitor the pediatric patients in this report. Increasing doses of heparin (0.1-0.4 U/ $\mathrm{mL}$ ) were added in vitro to pooled plasma from healthy children and adults, and the APTT subsequently measured.
Table 1. Protocol for systemic heparin administration and adjustment

1. Loading dose: heparin $50 \mathrm{U} / \mathrm{kg}$ i.v. over $10 \mathrm{~min}$

2. Initial maintenance dose: $20 \mathrm{U} / \mathrm{kg} / \mathrm{h}$

3. Adjust heparin to maintain APTT 55-85 s as follows:

\begin{tabular}{ccccc}
$\begin{array}{c}\text { APTT } \\
(\mathrm{s})\end{array}$ & $\begin{array}{c}\text { Bolus } \\
(\mathrm{U} / \mathrm{kg})\end{array}$ & $\begin{array}{c}\text { Hold } \\
(\mathrm{min})\end{array}$ & $\begin{array}{c}\text { Rate } \\
\text { change } \\
(\%)\end{array}$ & $\begin{array}{c}\text { Repeat } \\
\text { APTT }\end{array}$ \\
\hline$<50$ & 50 & 0 & $+10 \%$ & $4 \mathrm{~h}$ \\
$50-59$ & 0 & 0 & $+10 \%$ & $4 \mathrm{~h}$ \\
$60-85$ & 0 & 0 & 0 & Next day \\
$86-95$ & 0 & 0 & $-10 \%$ & $4 \mathrm{~h}$ \\
$96-120$ & 0 & 30 & $-10 \%$ & $4 \mathrm{~h}$ \\
$>120$ & 0 & 60 & $-15 \%$ & $4 \mathrm{~h}$
\end{tabular}

4. Obtain blood for APTT $4 \mathrm{~h}$ after administration of the heparin loading dose and $4 \mathrm{~h}$ after every change in the infusion rate.

5. When APTT values are therapeutic, a daily CBC and APTT.

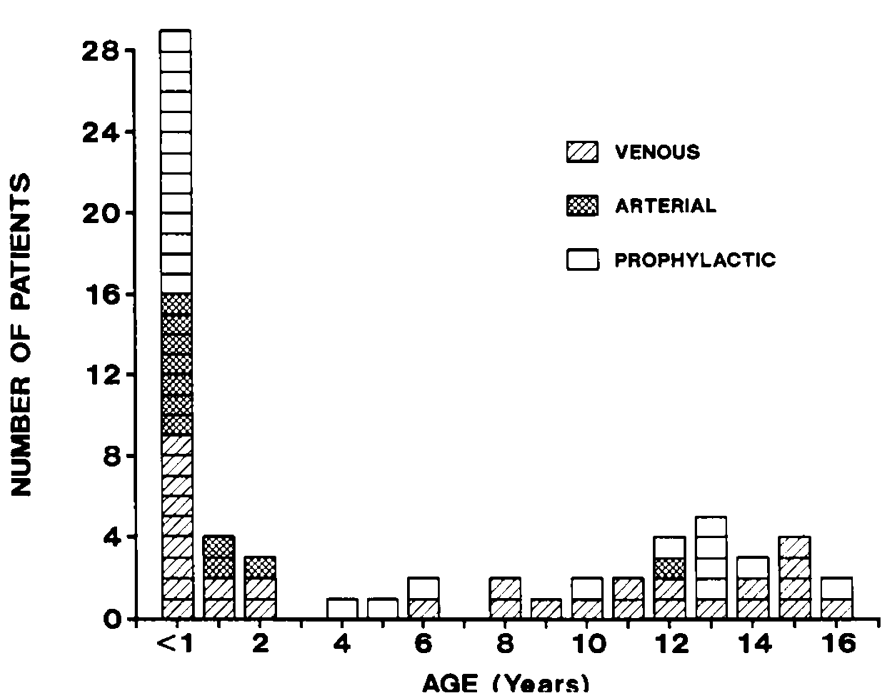

Fig. 1. Age distribution of 65 consecutive children receiving systemic dose heparin therapy. Children were grouped as follows: 30 children with documented DVT and/or pulmonary embolism (因), 11 children with arterial thrombosis $(\square)$, and 24 children receiving systemic dose prophylactic therapy $(\square)$.

\section{RESULTS}

Patient Population. There were 65 consecutive pediatric patients treated with heparin during the 10-mo study period; 38 males and 27 females. Of the 65 patients, 30 had DVT and/or PE, 11 had arterial thrombi, and the remaining 24 children (20 of whom had some form of $C H D)$ received heparin prophylactically. The age distribution of the entire patient population, and proportion of children in all three clinical groups is shown in Figure 1. There were two age groups in which the patients predominated. Twenty-nine (45\%) patients were less than $1 \mathrm{y}$ of age and $22(34 \%)$ were 10 y or older.

The indications for treatment with heparin varied with age (Table 2). Of the 29 children less than 1 y of age, CHD was the predominant underlying diagnosis $(22$ or $76 \%)$. Thirteen of the 29 children were infants less than 1 mo of age and again CHD was the predominant underlying diagnosis $(10$ or $77 \%)$. For the 22 children over 10 y of age, DVT was the predominant indication for heparin therapy ( 13 or $60 \%$ ).

The clinical presentation for children with venous or arterial disease varied widely depending upon the location of the thrombus and the underlying problem (Table 2).

Children with DVT. All 30 children with DVT had underlying primary disorders that consisted of: trauma/immobilization/ surgery (7), cancer (6), CHD (5), TPN (3), SLE (2), nephrotic 
Table 2. Indications for heparin therapy in 65 consecutive pediatric patients

\begin{tabular}{ll} 
Deep vein thrombosis $(n=30)$ & \\
Lower system & $15(1$ catheter related $)$ \\
Upper system & $9(7$ catheter related $)$ \\
Pulmonary embolism alone* & 1 \\
Central nervous system & 5 \\
Arterial thrombosis $(n=11)$ & \\
Femoral artery & 7 \\
Pulmonary artery & 3 \\
Axillary artery & 1 \\
Prophylactic therapy $(n=24)$ & \\
Blalock-Taussig shunt & 10 \\
Stents/grafts/dilation & 4 \\
Cardiomyopathy & 2 \\
Mechanical valve & 1 \\
Other congenital heart disease & 4 \\
Other & 3 \\
\hline
\end{tabular}

* Further three pulmonary emboli were documented in patients with deep vein thrombosis.

† All femoral artery thrombotic complications were after cardiac catheterization.

¥ Diagnosis for the other three children were: 1 ) severe nephrotic syndrome with a catheter in place, 2) balloon dilation of the superior vena cava which was narrowed after a previous catheter placed during infancy, and 3) a child with acute myeloblastic leukemia with a new catheter and a previous history of catheter related thrombi.

syndrome (2), pelvic kidney (1), arterial venous malformation (1), dehydration (1), sickle cell disease (1), obesity (1). Of the 30 patients with DVT, eight (27\%) were secondary to central venous catheters placed for the treatment of the primary problem. A further five were located in the central nervous system.

Children without DVT. Of the 11 children presenting with arterial thrombi, six were in the femoral artery secondary to cardiac catheterization. Three children had pulmonary artery thrombi secondary to therapeutic interventions related to $\mathrm{CHD}$.

Radiologic evaluation. DVT and/or PE were diagnosed in all 30 children on the basis of objective testing. Twenty-four children had DVT documented by venography (12) or duplex/ultrasound (12). Fifteen of these DVT were located in the lower system, and nine in the upper system. PE was diagnosed by V/Q scans in three patients, two with documented DVT and one without a documented primary source. The remaining five children had venous disease in the central nervous system which was documented with either computed axial tomography or magnetic resonance imaging.

The 11 children with arterial thrombi were diagnosed by either duplex/ultrasound (2), at the time of cardiac catheterization (3) or by absent pulses following catheterization (6).

Evaluation of the Heparin Protocol. The APTT values were similar in all groups before treatment with heparin (Table 3 ). Thirty-six of the 65 children received a bolus of $50 \mathrm{U} / \mathrm{kg}$ of heparin. Of these 36 , only $39 \%$ achieved a minimal level APTT (above $55 \mathrm{~s}$ ) 4 to $6 \mathrm{~h}$ later (Table 3 ).

The goal of maintenance therapy was to achieve an APTT value between 55 and $85 \mathrm{~s}$. After $24 \mathrm{~h}$ of heparin maintenance, initiated at $20 \mathrm{U} / \mathrm{kg} / \mathrm{h}, 68 \%$ of children had achieved a minimal level APTT, and by $48 \mathrm{~h}$ the proportion increased to $81 \%$ (Fig. 2). Throughout the course of treatment APTT values were above the minimal therapeutic level of $63 \%$ of the time and within the therapeutic range $43 \%$ of the time (Table 3). The heparin nomogram successful achieved a therapeutic APTT after one adjustment in $56 \%$ of children, two adjustments in $22 \%$ and three or more adjustments in 33\%. The infants less than $1 \mathrm{y}$ of age required the largest number of adjustments. APTT values outside the therapeutic range were twice as likely to be low as high. The overall average amount of heparin required to maintain therapeutic APTT values was $22 \mathrm{U} / \mathrm{kg} / \mathrm{h}$ (Table 3). A subanalysis of
Table 3. Heparin therapy in children*

\begin{tabular}{lcccc}
\hline & DVT & Arterial & $\begin{array}{c}\text { Prophy- } \\
\text { lactic }\end{array}$ & Total \\
\hline Number & 30 & 11 & 24 & 65 \\
Pre APTT (s) & $29 \pm 1.2$ & $32 \pm 1.6$ & $31 \pm 2.2$ & $30 \pm 1.0$ \\
Post Bolus APTT (s) & & & & \\
$\quad$ Number & 21 & 5 & 10 & 36 \\
$\quad$ Therapeutic (\%) & 19 & 0 & 10 & 14 \\
$\quad$ High (\%) & 17 & 40 & 30 & 25 \\
$\quad$ Low (\%) & 64 & 60 & 60 & 61 \\
First Therapeutic & $65 \pm 1.5$ & $64 \pm 3.1$ & $64 \pm 1.9$ & $65 \pm 1.1$ \\
$\quad$ APTT (s) & & & & \\
Percent (\%) of time & & & & \\
$\quad$ APTT was: & 48 & 24 & 38 & 43 \\
$\quad$ Therapeutic & 22 & 27 & 12 & 20 \\
High & 31 & 49 & 50 & 37 \\
$\quad$ Low & $20 \pm 1.3$ & $26 \pm 2.8$ & $20 \pm 1.1$ & $22 \pm 1.0$ \\
Amount of heparin/ & & & & \\
$\quad$ kg/h & & & & \\
\hline
\end{tabular}

* Data are expressed as mean values \pm SEM unless indicated otherwise.

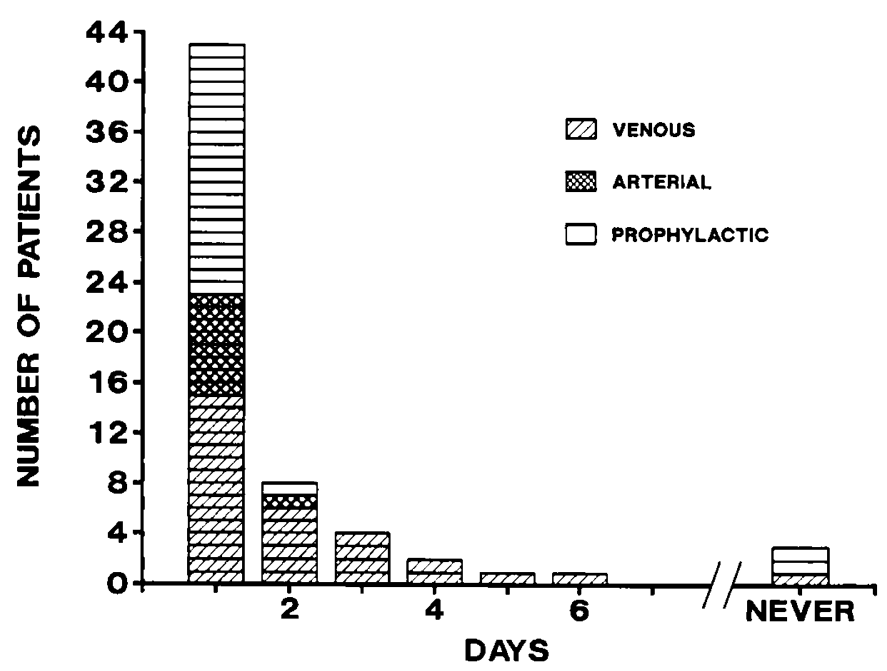

Fig. 2. Day on which children achieved the minimal therapeutic APTT. Only 61 patients were evaluated because in four children the minimum APTT value was modified due to a very high risk of bleeding. Children were grouped as follows: children with documented DVT and/ or pulmonary embolism (ש), children with arterial thrombosis ( $\square$ ), and children receiving systemic dose prophylactic therapy ( $\square$ ).

infants less than $1 \mathrm{y}$ of age showed that they required slightly more heparin at $28 \mathrm{U} / \mathrm{kg} / \mathrm{h}$ and that older children required 20 $\mathrm{U} / \mathrm{kg} / \mathrm{h}$.

The duration of heparin therapy differed depending upon the indication for treatment (Fig. 3). Children with DVT were treated for the longest period of time (median: $8 \mathrm{~d}$ ) compared to children with arterial thrombi (median: $3 \mathrm{~d}$ ) and children requiring prophylactic therapy (median: $4 \mathrm{~d}$ ).

Ex vivo heparin levels were also measured in 52 of the 65 children in this report. Using heparin levels as the "gold standard" (1), APTT values correctly identified children as being therapeutic or not $73 \%$ of the time. However, the correlation between APTT values and heparin levels was relatively weak (antifactor $\mathrm{Xa} . \mathrm{r}^{2}=0.51$; protamine sulphate. $r^{2}=0.55$ ). The correlation between APTT values and heparin levels measured ex vivo on plasma samples [either anti-factor $\mathrm{Xa}(n=82)(18)$ or protamine sulphate neutralization $(n=51)(19)]$ is shown in Figure 4. To monitor heparin, children had an average of two venipunctures per day for APTT measurements.

Responsiveness to Heparin In Vitro. The in vitro correlation between APTT values and heparin added to pooled plasma from adults and children was excellent and similar (Table 4; adult, $r^{2}$ 


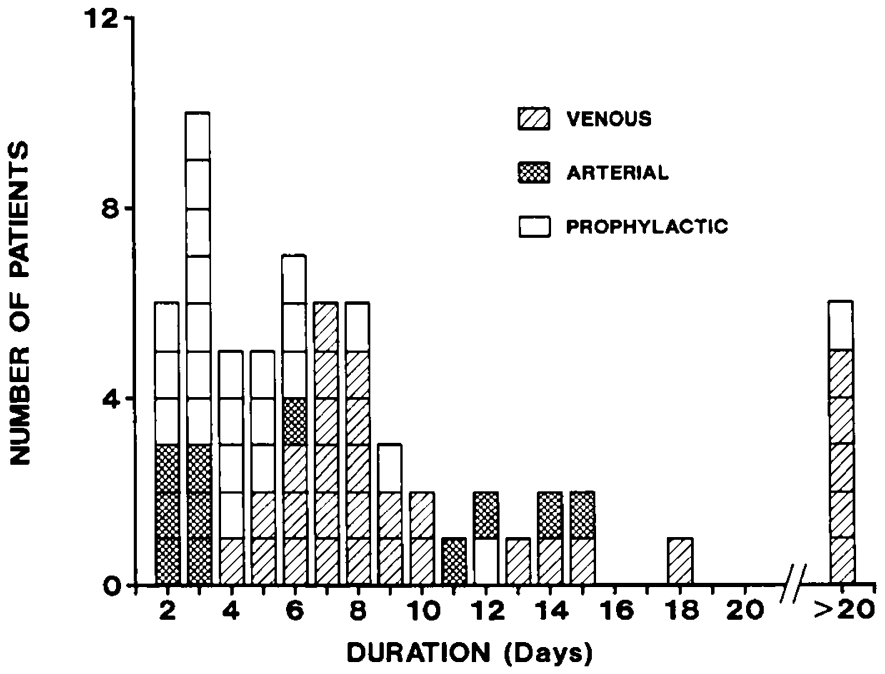

Fig. 3. Duration of therapy for 65 consecutive children receiving systemic dose heparin. Children with venous thromboembolic disease (四) were treated for a median of $8 \mathrm{~d}$, with arterial thrombi $(\square)$ for a median of $3 \mathrm{~d}$, and prophylactically $(\square)$ for a median of $4 \mathrm{~d}$.
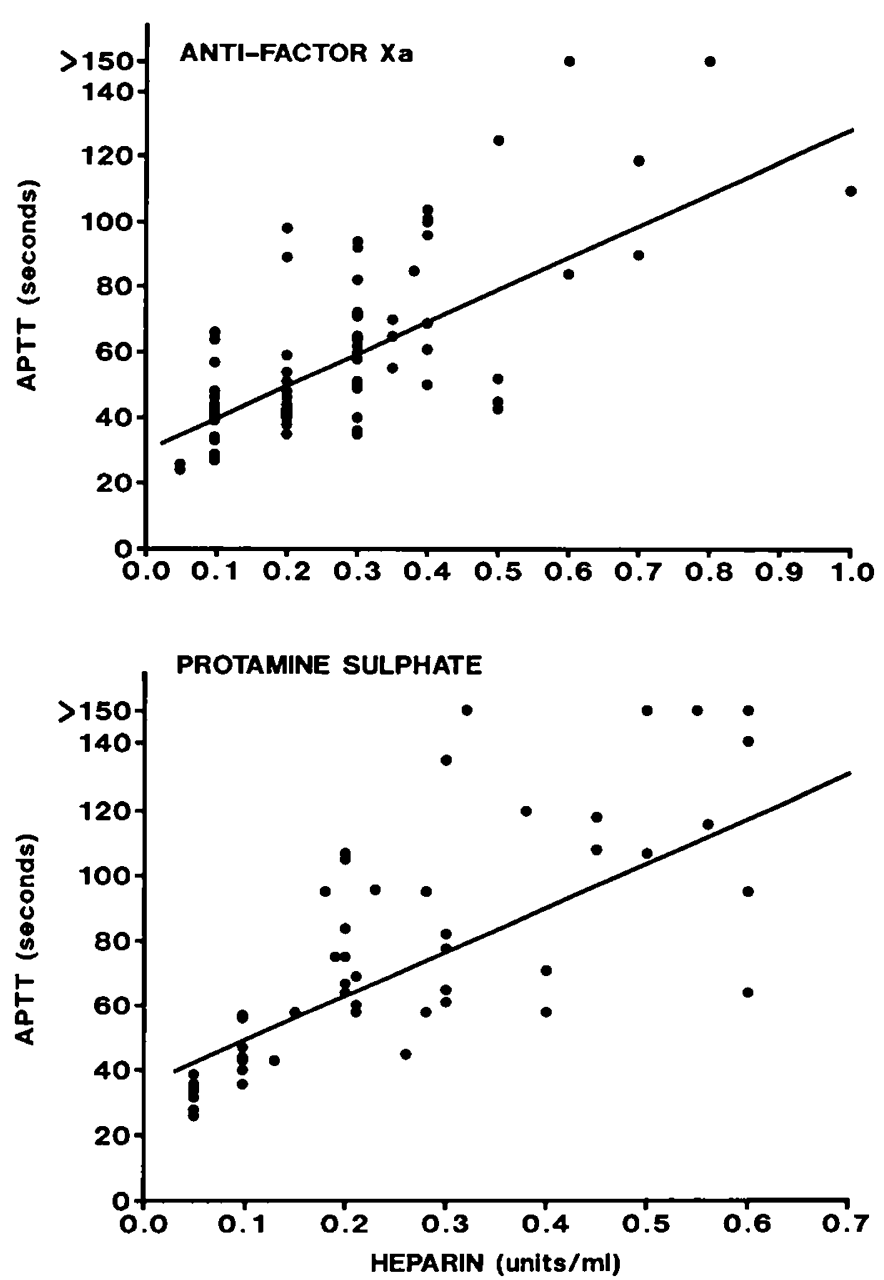

Fig. 4. Relationship between APTT values and heparin levels measured by an anti-factor Xa assay (18) (upper panel) or thrombin clotting time assay (19) (lower panel) on ex vivo plasma samples from 52 of 65 pediatric patients. Using heparin levels as "gold standard" test for heparin concentrations, APTT values accurately reflected heparin concentrations $73 \%$ of time.
Table 4. In vitro comparison of APTT response to heparin added to pooled plasmas from adults and children*

\begin{tabular}{lcccc}
\hline & \multicolumn{4}{c}{ Heparin concentration (units/mL) } \\
\hline APTT (s) & 0 & 0.1 & 0.2 & 0.4 \\
Adult & $30 \pm 0.6$ & $39 \pm 1.4$ & $64 \pm 5.9$ & $128 \pm 9.2$ \\
Children & $31 \pm 0.3$ & $38 \pm 0.4$ & $59 \pm 1.3$ & $132 \pm 5.8$ \\
\hline
\end{tabular}

* All pools were studied on four occasions. Data expressed as mean \pm SEM. Children were evenly distributed from ages 1 to $16 \mathrm{y} ; p<0.001$.

$=0.90$; children, $r^{2}=0.92$ ). The baseline APTT values in children and adults (Table 4) were similar to the 65 children receiving heparin in vivo (Table 3 ).

Clinical outcome. All 65 children were evaluated prospectively for bleeding complications and/or recurrent thromboembolic disease. Heparin therapy was discontinued in one child with a mechanical heart valve, who bled after tonsillectomy with an APTT greater than $150 \mathrm{~s}$ at the time. The bleeding resolved uneventfully and no other child had significant bleeding. After completion of heparin therapy and within $3 \mathrm{mo}$ of the initial event, two children had documented recurrent venous disease (7\%), one in the form of a new PE and the second with recurrent catheter related thrombi. Two children had clinically suspected recurrent disease. One child with a sagittal sinus thrombus developed recurrent headaches with vomiting (the original symptom), that resolved when heparin was resumed. The second child developed tachypnea with a matched ventilation/perfusion defect. All four children had subtherapeutic APTT values for varying periods of time during their previous heparin therapy. Two children with femoral artery thrombi secondary to cardiac angiography went on to require thrombolytic therapy.

\section{DISCUSSION}

Heparin is the initial treatment of choice for most patients at risk for, or with, thromboembolic complications. We prospectively monitored 65 consecutive pediatric patients to determine the epidemiologic characteristics of children receiving heparin at a tertiary care center and the efficacy and safety of systemic heparin therapy in the same population. Children receiving systemic heparin could be readily classified into specific clinical groups. The majority of children required 24 to $48 \mathrm{~h}$ of treatment to achieve a therapeutic level of heparin based upon the APTT. Maintenance heparin requirements were age dependant with children less than 1 y of age requiring $25 \%$ more heparin compared to older children. The risk of documented recurrent thrombotic disease (7\%) was at least as frequent as bleeding complications (2\%).

Demographic information for consecutive, prospectively studied pediatric patients requiring systemic heparin therapy, has not been previously described. The clinical problems were diverse with all children having at least one acquired disorder $(4,5,21$, 22). Three groups of patients were identified: children with DVT, children with arterial thrombi, and children requiring systemic prophylaxis. DVT occurred more frequently in teenagers $(60 \%)$ and were associated with central venous catheters placed in the upper venous system (30\%). Arterial thrombi after cardiac angiography and prophylactic heparin after specific cardiac procedures for CHD were more common in children less than $1 \mathrm{y}$ of age $(76 \%)$ (Table 2; Fig. 1) (15). The duration of therapy was dictated by the reason for treatment and followed established practices at our institution and in the literature.

Heparin therapy was administered and monitored according to a predetermined protocol using the APTT test (Table 1). The APTT was chosen because it is convenient, widely available, and reflects heparin's anticoagulant activities which are closely related to, but not synonymous with, heparin's antithrombotic activities (1). The activated clotting time was not chosen because it is not as reproducible as the APTT, is highly operator-dependent, and significantly influenced by the machine chosen (23-25). Heparin 
assays were not chosen for routine monitoring because of the lack of availability on a routine basis and cost involved.

The therapeutic range for heparin reflects a minimum adequate level to prevent extension or recurrence and a maximum level to decrease the risk of bleeding $(1,26,27)$. Unfortunately, different APTT reagents have widely varying sensitivities to heparin that significantly affect the therapeutic range (28). To correct for this variability, the therapeutic range in APTT values needs to be standardized to reflect plasma heparin concentrations of 0.2 to $0.4 \mathrm{U} / \mathrm{mL}$ by protamine sulphate assay of 0.35 to 0.7 $\mathrm{U} / \mathrm{mL}$ by anti-factor Xa activity $(1,18,19)$. Thus, an APTT of 1.5 to 2 times the baseline APTT value cannot be assumed to reflect the therapeutic range. In our study, APTT values correctly predicted whether heparin concentrations were therapeutic $73 \%$ of the time. However, the correlation between heparin levels measured with either of two reference heparin tests and APTT values was relatively weak. In contrast, in vitro correlation between APTT values and heparin levels was excellent. Both of these observations are similar to the experience in adults (29).

The therapeutic range recommended for heparin therapy in adult patients with DVT was used in our patients for several reasons. First, this reflected current practice in pediatric centers. Second, the outcome for our pediatric patients could be compared descriptively to studies in adult patients monitored in a similar fashion $(30,31)$. Accurate comparisons cannot be made because heparin requirements for adults are not calculated based on body weight $(1,30,32,33)$. However, the same general principles of heparin therapy will likely apply to children as well as adults. Third, the efficacy and safety of this approach required evaluation to provide a basis for future strategies directed at optimizing anticoagulant therapy in children.

Recent studies in adults with DVT have shown that achieving a therapeutic APTT early (within $48 \mathrm{~h}$ of initiating treatment) significantly reduces the rate of recurrence $(30,34-37)$. Informal audits of heparin therapy in adult patients have shown that doseadjustment practices are often inadequate delaying the achievement of an APTT value above the minimum therapeutic level $(20,38,39)$. When adult patients are monitored closely with a nomogram, APTT values above the minimal level are achieved in $82 \%$ of patients after $24 \mathrm{~h}$ and in $91 \%$ after $48 \mathrm{~h} \mathrm{(20)}$. Pediatric patients with DVT in this report were monitored with a modified form of this nomogram (Table 1) (20). APTT values were slower to achieve the lower therapeutic limit by $24 \mathrm{~h}(61 \%)$ and by 48 h (75\%) compared to adults. Probable explanations were a bolus dose that was too low $(50 \mathrm{U} / \mathrm{kg})$ and increased maintenance requirements, particularly in younger children (Table 3; Fig. 2). The results for children with DVT were similar to the analyses of the entire group (Table 3; Fig. 2).

There are at least two plausible explanations for the high heparin requirement in young children. First, heparin is cleared more quickly in the young compared to the adult in both animal models $(6)$ and in man $(7,8)$. Second, the delay in the diagnosis of DVT in children may result in more extensive disease at the time of presentation which may accelerate the clearance of heparin $(40,41)$. Recurrent disease was documented in two of the 30 children with DVT and suspected clinically in a further two. No child with DVT had bleeding complications, and only one child in the entire study had heparin therapy stopped because of local bleeding after a tonsillectomy.

In summary, this study has identified the demographic features of children receiving heparin in tertiary care pediatric centers. A uniform protocol that reflected current heparin administration in children was evaluated. The rate at which therapeutic heparin values were achieved was slower than that reported for adults likely reflecting the need for a larger bolus dose and increased maintenance doses of heparin for younger children. Pending additional studies, it would be reasonable clinical practice to increase the heparin bolus dose to $75 \mathrm{U} / \mathrm{kg}$ and increase the maintenance dose in infants less than 1 y of age to $28 \mathrm{U} / \mathrm{kg} / \mathrm{h}$.
Further studies are needed to establish an optimal heparin protocol for children.

Acknowledgments. The authors acknowledge the assistance of Annette Brown, the technical assistance of Mrs. Patsy Vegh, and the clinical coagulation laboratory at HSC, Toronto, Canada.

\section{REFERENCES}

1. Hirsh J 1991 Heparin. N Engl J Med 324:1565-1574

2. Schmidt B, Andrew M 1992 Report of scientific and standardization subcommittee on neonatal hemostasis diagnosis and treatment of neonatal thrombosis. Thromb Haemost 67:381-382

3. Andrew M 1993 Hemorrhagic and thrombotic complications in children. In: Colman RW, Hirsh J, Marder VJ, Salzman EW (eds) Hemostasis and Thrombosis: Basic Principles and Clinical Practice, JB Lippincott, Philadelphia

4. Wise RC, Todd JK 1973 Spontaneous, lower-extremity venous thrombosis in children. Am J Dis Child 126:766-769

5. Bernstein D, Coupey S, Schonberg SK 1986 Pulmonary embolism in adolescents. Am J Dis Child 140:667-671

6. Andrew M, Ofosu FA, Schmidt B, Brooker L, Hirsh J, Buchanan MR 1988 Heparin clearance and ex vivo recovery in newborn piglets and adult pigs. Thromb Res 52:517-527

7. McDonald MM, Jacobson LJ, Hay WW, Hathaway WE 1981 Heparin clearance in the newborn. Pediatr Res 15:1015-1018

8. Turner Gomes S, Nitschmann E, Benson L, Burrows P, Andrew M 1993 Heparin is cleared faster in children with congenital heart disease than adults. J Am Coll Cardiol 21:59A(abstr)

9. Schmidt B, Ofosu FA, Mitchell L, Brooker LA, Andrew M 1989 Anticoagulant effects of heparin in neonatal plasma. Pediatr Res 25:405-408

10. Vieira A, Ofosu F, Andrew M 1991 Heparin sensitivity and resistance in the neonate: an explanation. Thromb Res 63:85-99

11. Vermylen CG, Levin M, Lanham JG, Hardisty RM, Barratt TM 1987 Decreased sensitivity to heparin in vitro in steroid-responsive nephrotic syndrome. Kidney Int 31:1396-1401

12. Barnard DR, Hathaway WE 1979 Neonatal thrombosis. Am J Pediatr Hematol Oncol 1:235-244

13. Van Damme-Lombaerts R, Proesmans W, Van Damme B, Eeckels R, Binda Ri Mucka P, Mercieca V, Vletinck R, Vermylen J 1988 Heparin plus dipyridamole in childhood hemolytic-uremic syndrome: a prospective, randomized study. J Pediatr 113:913-918

14. Szelid Z, Bereczky J, Nagymanyai R, Ruszinko V 1986 Heparin prophylaxis of Henoch-Schoenlein nephropathy. Acta Paediatr Hung 57:57-60

15. Ino T, Benson LN, Freedom RM, Barker GA, Zipursky A, Rowe RD 1988 Thrombolytic therapy for femoral artery thrombosis after pediatric cardiac catheterization. Am Heart J 115:633-639

16. McDonald MM, Hathaway WE 1982 Anticoagulant therapy by continuous heparinization in newborn and older infants. J Pediatr 191:451-457

17. Woods A, Vargas J, Berri G, Kreutzer G, Meschengieser S, Lazzari MA 1986 Antithrombotic therapy in children and adolescents. Thromb Res 42:289301

18. Teien AN, Lie M 1977 Evaluation of amidolytic heparin assay method: increased sensitivity by adding purified antithrombin III. Thromb Res 10:399-410

19. Penner JA 1974 Experience with a thrombin clotting time assay for measuring heparin activity. Am J Clin Pathol 61:645-653

20. Cruickshank MK, Levine MN, Hirsh J, Roberts R, Siguenza M 1991 A standard heparin nomogram for the management of heparin therapy. Arch Intern Med 151:333-337

21. Nguyen LT, Laberge JM, Guttman FM, Albert D 1986 Spontaneous deep vein thrombosis in childhood and adolescence. J Pediatr Surg 21:640-643

22. Buck JR, Connors RH, Coon WW, Weintraub WH, Wesley JR, Coran AG 1981 Pulmonary embolism in children. J Pediatr Surg 16:385-391

23. Green TP, Ischam-Schopf B, Steinhorn RH, Smith C, Irmiter RJ 1990 Whole blood activated clotting time in infants during extracorporeal membrane oxygenation. Crit Care Med 18:494-498

24. Andrew M, MacIntyre B, Williams WG, Gruenwald C, Johnston M, Burrows F, Wang E, MacMillan J, Adams M 1993 Heparin therapy during cardiopulmonary bypass requires ongoing quality control. Thromb Haemost (in press)

25. Keeth J, Trickey T, King E, Stafford T, McInnis R, Reed C 1988 A clinical evaluation of the hemotec ACT. Proc Am Acad Cardio Perf 9.22-25

26. Levine MN, Hirsh J 1986 Hemorrhagic complications of anticoagulant therapy. Semin Thromb Hemost 12:39-57

27. Nieuwenhuis HK, Albada J, Banga JD, Sixma JJ 1991 Identification of risk factors for bleeding during treatment of acute venous thromboembolism with heparin or low molecular weight heparin. Blood 78:2337-2343

28. Shojania AM, Tetreault J, Turnbull G 1988 The variations between heparin sensitivity of different lots of activated partial thromboplastin time reagent produced by the same manufacturer. Am J Clin Pathol 89:19-23

29. Brill-Edwards P, Ginsberg JS, Johnston M, Hirsh J 1993 Establishing a therapeutic range for heparin therapy. Ann Intern Med 119:104-109

30. Hull RD, Raskob G, Hirsh J, Jay RM, LeClerc JR, Geerts WH, Rosenbloom D, Sackett DL, Anderson C, Harrison L 1986 Continuous intravenous heparin compared to intermittent subcutaneous heparin in the initial treatment of proximal vein thrombosis. N Engl J Med 315:1109-1114 
31. Chiu HM, Hirsh J, Yung WL, Regoeczi E, Gent M 1977 Relationship between the anticoagulant and antithrombotic effects of heparin in experimental venous thrombosis. Blood 49:171-184

32. Gallus A, Jackaman J, Tillett J, Mills W, Wycherley A 1986 Safety and efficacy of warfarin started early after submassive venous thrombosis or pulmonary embolism. Lancet 2:1293-1296

33. Hull RD, Raskob GE, Rosenbloom D 1990 Heparin for 5 days as compared with 10 days in the initial treatment of proximal venous thrombosis. $N$ Engl J Med 322:1260-1264

34. Basu D, Gallus A, Hirsh J, Cade J 1972 A prospective study of the value of monitoring heparin treatment with the activated partial thromboplastin time. N Engl J Med 287:324-327

35. Turpie AGG, Robinson JG, Doyle DJ 1989 Comparison of high-dose with low-dose subcutaneous heparin to prevent left ventricular mural thrombosis in patients with acute transmural anterior myocardial infarction. $\mathrm{N}$ Engl $\mathrm{J}$ Med 320:352-357

36. Kaplan K, Davison R, Parker M, Mayberry B, Feiereisel P, Salinger M 1987
Role of heparin after intravenous thrombolytic therapy for acute myocardia infarction. Am J Cardiol 59:241-244

37. Camilleri JF, Bonnet JL, Bouvier JL 1988 Thrombolyse intraveineuse dan l'infarctus du myocarde: influence de la qualite de l'anticoagulation sur le taux de recidives precoces d'angor ou d'infarctus. Arch Mal Coeur 81:10371041

38. Wheeler AP, Jaquiss RD, Newman JH 1988 Physician practices in the treatment of pulmonary embolism and deep vein thrombosis. Arch Intern Med 148:1321-1325

39. Fennerty A, Thomas P, Backhouse G, Bentley P, Campbell IA, Routledge PA 1985 Audit of control of heparin treatment. Br Med J 290:27-28

40. Hirsh J, van Aken WG, Gallus AS, Dollery CT, Cade JF, Yung WL 1976 Heparin kinetics in venous thrombosis and pulmonary embolism. Circulation 53:691-695

41. Chiu HM, van Aken WG, Hirsh J, Regoeczi E, Horner AA 1977 Increased heparin clearance in experimental pulmonary embolism. J Lab Clin Med 90:204-215 